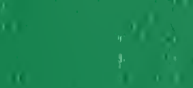

72

$\therefore x^{2}$

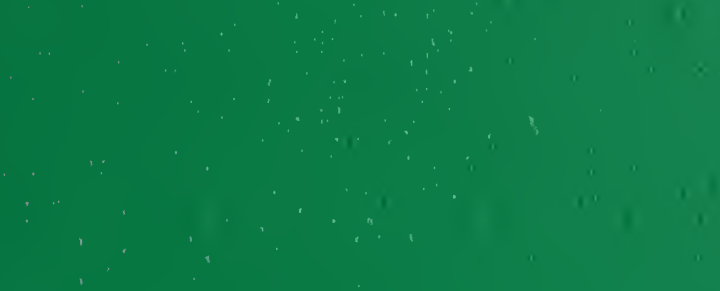



LIERARY

FOYAL ONTARIO M!ISFIJA 


\section{Digitized by the Internet Archive in 2012 with funding from Royal Ontario Museum}




$\mathrm{ROM} \quad \begin{aligned} & \text { Life Sciences } \\ & \text { Occasional Papers }\end{aligned}$

Royal Ontario Museum

Nov. 15, 1968

No. 12

\title{
A New Species of Bat of the Genus Sturnira (Family Phyllostomatidae) from Northwestern South America
}

\author{
by R. L. Peterson ${ }^{1}$ and J. R. Tamsitt ${ }^{1}$
}

The collections of New World bats of the Institut Royal des Sciences Naturelles de Belgique contain a male and a female Sturnira catalogued on April 19th, 1874, from an unspecified locality in Ecuador. The specimens, both full adults preserved in alcohol, exceed in size all known species of the genus except Sturnira magna de la Torre, 1966. The pelage is so completely faded as to provide no indication of colouration, although the unbleached, protected areas on the side of the abdomen are still quite dark, perhaps darker than S. magna. When the skulls were extracted they proved to be strikingly different from $S$. magna. News was received that Mr. Maurice Thomas and Dr. Andrew Arata, of Tulane University, had obtained a specimen of a large Sturnira in southwestern Colombia. Their example, kindly forwarded to us, proves to be virtually identical in size and cranial details and is a well-made skin providing details of colouration. In tribute to their contributions to the knowledge of South American bats, we take pleasure in proposing that this new species be known as:

\section{Sturnira aratathomasi, sp. $n$.}

Holotype-Univ. del Valle-Tulane No. 635 (to be deposited in the Smithsonian Institution, Washington, D.C., as No. 395158), adult male,

1. Department of Mammalogy, Royal Ontario Museum. skin and skull, collected by Maurice Thomas, December 1, 1966, $2 \mathrm{~km}$ south of Pance (approximately $20 \mathrm{~km}$ southwest of Cali), Dept. of Valle, Colombia, at 1650 metres elevation (see Figs. 1 and 2).

Paratypes-Institut Royal des Sciences Naturelles de Belgique, adult male and female, Reg. 237, preserved in alcohol, skulls removed; from an unknown locality in Ecuador, collected prior to April 19, 1874. (The female is to be deposited in the Royal Ontario Museum, ROM No. 46349 ; see Figs. 3 and 4.)

Range-Known from southwestern Colombia and also from Ecuador (possibly restricted to the Pacific side of the Andes).

Diagnosis-A large species equal to or larger than $S$. magna from the Amazonian area of Peru (see Table I and Figs. 1 to 4) but differing from that species in having a more depressed and elongated rostrum; a much longer and relatively narrower anterior nasal aperture; anterior palatine foramina much longer and divided by a much narrower septum; posterior palate ending in a long narrow $\mathrm{V}$ instead of a shorter arch shape; upper inner incisors much longer and centrally pointed instead of relatively broad and in near contact terminally; upper canines noticeably longer and directed more anteriorly; upper premolars much larger 

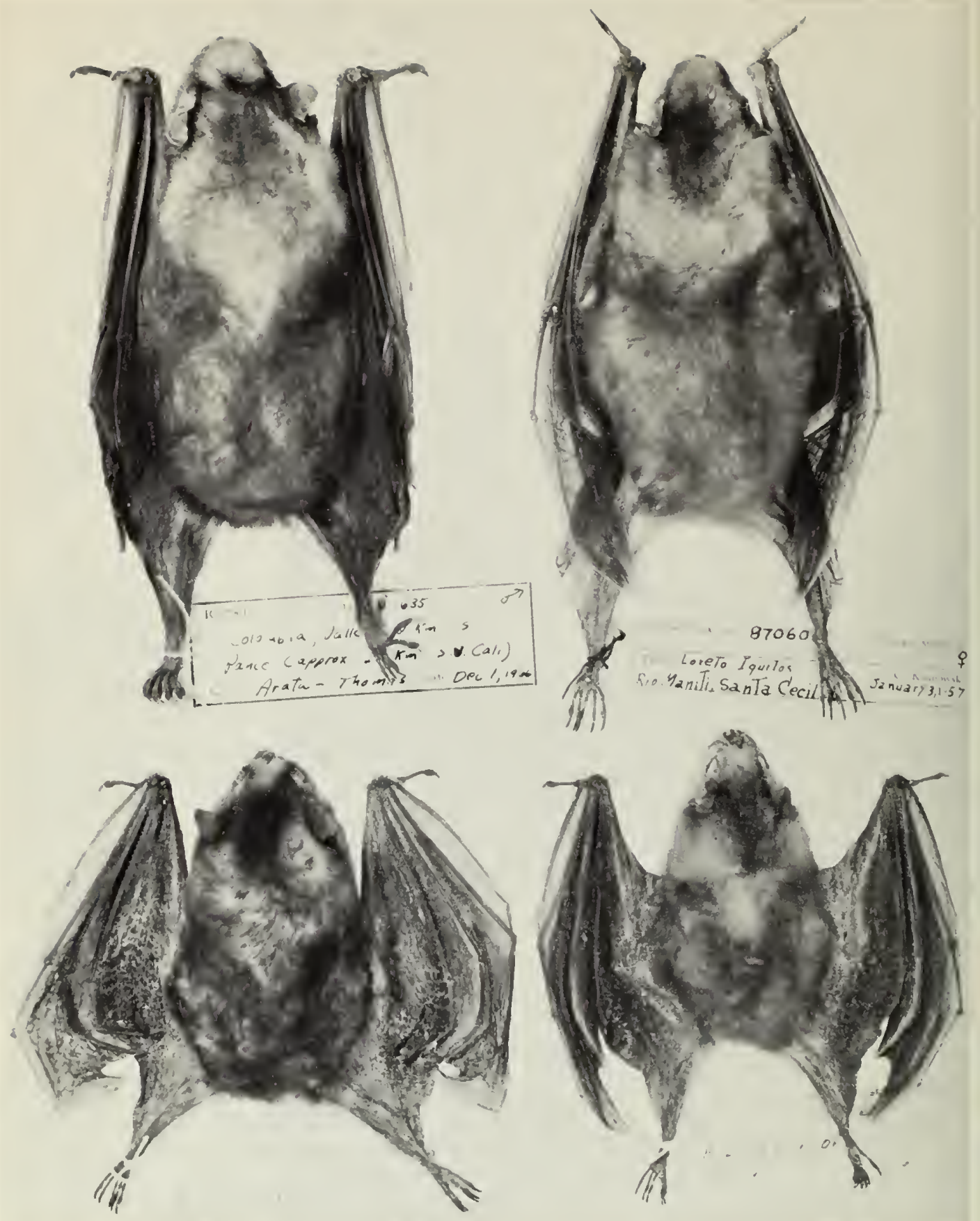

Figure 1

Skins of four species of Sturnira. Photos by L. R. Warren.

Top-Left-Sturnira aratathomasi, holotype

Right-S. magna, FMNH No. 87060 \%, paratype

Bottom-Left-S. tildae, ROM No.31611 Right-S. lilium, ROM No. 31791 
but relatively smaller than $\mathrm{M}^{1} ; \mathrm{M}^{3}$ relatively smaller than $\mathrm{M}^{2}$; and $\mathrm{M}^{3}$ with strongly developed antero-internal cusps and with deep sculpturing between them and the buccal cusps. The lower incisors are bifid with the crowns flaring from relatively narrow bases (anterior view). The lower canines are strikingly longer (higher) than in S. magna, and the premolars differ in shape (lateral view), with the central cusp positioned farther anteriorly and a distinct posterior cusp formed by the much lower posterior profile, giving the effect of much higher and narrower premolars. $\mathbf{M}_{3}$ is actually, as well as relatively, smaller than in S. magna. $\mathrm{M}_{1}$ and $\mathrm{M}_{2}$ have distinct lingual and buccal cusps not unlike those of $S$. lilium. In pelage colouration, $S$. aratathomasi is dark greyish below as opposed to yellowish or golden-brown in S. magna but with the same tones predominating above, although paler as a result of light banding of the fur (more sharply defined in the former). The tibia, foot and forearm are also darker, and the tragus is longer, wider and less sharply pointed than in $S$. magna. The large size of the body, wing and skull distinguish $S$. aratathomasi (and $S$. magna) from all other known species of Sturnira.

Description of the holotype-Body size large (total length, $101 \mathrm{~mm}$; forearm length, $59 \mathrm{~mm}$ ). Dorsal colouration (Ridgway, 1912) dull Fuscous-black, lightest anteriorly, paler posteriorly. Head Buffy-brown, with Mummybrown hairs around eyes and between ears; nape Fuscous, shading to Fuscous-black on rump; underparts varying from light Mummybrown on chin to Mouse-grey on throat, drab on chest to Fuscous on abdomen and lateral areas. Fuscous-black dorsally and Fuscous ventrally along the insertion of the wing membrane to the base of the humerus. Dorsal hairs quadricolour. Hair at nape and shoulders with base white; epibasal band light grey (about $2 \mathrm{~mm}$ ); broad conspicuous subterminal band white (about $4 \mathrm{~mm}$ ); short terminal band (about $2 \mathrm{~mm}$ ) greyish-brown. On neck and shoulders the subterminal white band shows through to the surface to give a grizzled appearance. Posteriorly the epibasal band becomes darker and the subterminal white band becomes narrower (about $2.5 \mathrm{~mm}$ ) and less conspicuous. Rump hairs slightly shorter. Hair at throat short (about $5 \mathrm{~mm}$ ), base white; middle band pale grey $(2 \mathrm{~mm})$; tips silver
( $2 \mathrm{~mm})$. Chest hairs with base white; middle band pale greyish-brown ( $2 \mathrm{~mm})$; tip very pale silver or silver-brown blending to pale golden ( $2 \mathrm{~mm})$. On the abdomen the epibasal and subterminal bands become darker and wider (2.5 $\mathrm{mm}$ ) posteriorly, and the terminal band changes from silver to golden-brown. Long (about $10 \mathrm{~mm}$ ) fringing hairs, with base white at the posterior of rump; wide epibasal band brown ( $3 \mathrm{~mm})$; subterminal band grey $(2 \mathrm{~mm})$; wide terminal band (2-4 mm) dark brown. Noseleaf, lips, fingers, legs and feet blackish; wing membranes blackish and darker than pelage of upper parts; ear grey; tragus pale grey, tip and edge of outer margin black. Pelage soft and woolly. Proximal half of forearm lightly haired, dorsal hairs brown, ventral hairs silvery-brown. Posteriolateral edge of interfemoral membrane fringed with brown hairs, about $4 \mathrm{~mm}$ at the level of knee.

Feet large $(21 \mathrm{~mm})$, sparsely covered with hair to tip of toes, a few long hairs (approx. $2 \mathrm{~mm}$ ) at base of claws; rudimentary calcar represented by small $(2 \mathrm{~mm})$ projection; wing membrane from the side of the ankle at the base of the metatarsus; ears short, tip rounded, the outer margin emarginate in its distal half, the inner margin concave in its proximal half and evenly curved distally; tragus elongate and tapering distally, about a third as high as the ear and nearly of the same width for the basal two-thirds of its length, the tip subacute and pointed toward outer margin; inner margin of tragus entire; outer margin irregular distally, with a notch opposite the base of the inner margin and a distinct rounded lobule at the base. Noseleaf short and broad, tip blunt, lancet about as high as wide, without a vertical median ridge on the anterior surface; horseshoe of noseleaf with base fused to upper lip. Chin ornaments (from alcoholic paratypes) composed of a central large oblong dorsal element and four pairs of lateroventrally arranged circular elements (warts).

Remarks-A striking feature of the skull of $S$. aratathomasi is the profile of the long rostrum which is carried forward by the protruding inner incisors. The general conformation of the canine-molar dentition is similar to $S$. lilium, while that of $S$. magna approaches $S$. ludovici. The shape of the inner upper incisors is subject to considerable variation in S. lilium, S. tildae and $S$. ludovici, and individual specimens sometimes approach the shape of the three 
known examples of S. aratathomasi. However, we observed none with incisors that protruded so strongly anteriorly. A great majority of specimens of $S$. lilium and $S$. tildae examined exhibited a weak bifid condition, as illustrated by de la Torre (1959, Fig. 5), whereas the central upper incisors of most of our smaller sample of $S$. ludovici approached the shape of $S$. aratathomasi, rather than the example illustrated by de la Torre (op.cit.).

Shoulder glands and the characteristic staining of the hairs associated with their openings are apparently lacking in the male holotype of $S$. aratathomasi. Although generally characteristic of adult male Sturnira, the presence and prominence of the stained shoulder hairs (epaulettes) is variable in both sexes and may be correlated with the attainment of reproductive maturity, reproductive state or breeding season. A series of the smaller species $S$. lilium from British Honduras and Guyana, preserved as skins and skulls in the ROM collection, illustrate this variability. Of 30 males, nine were young adults, and 21
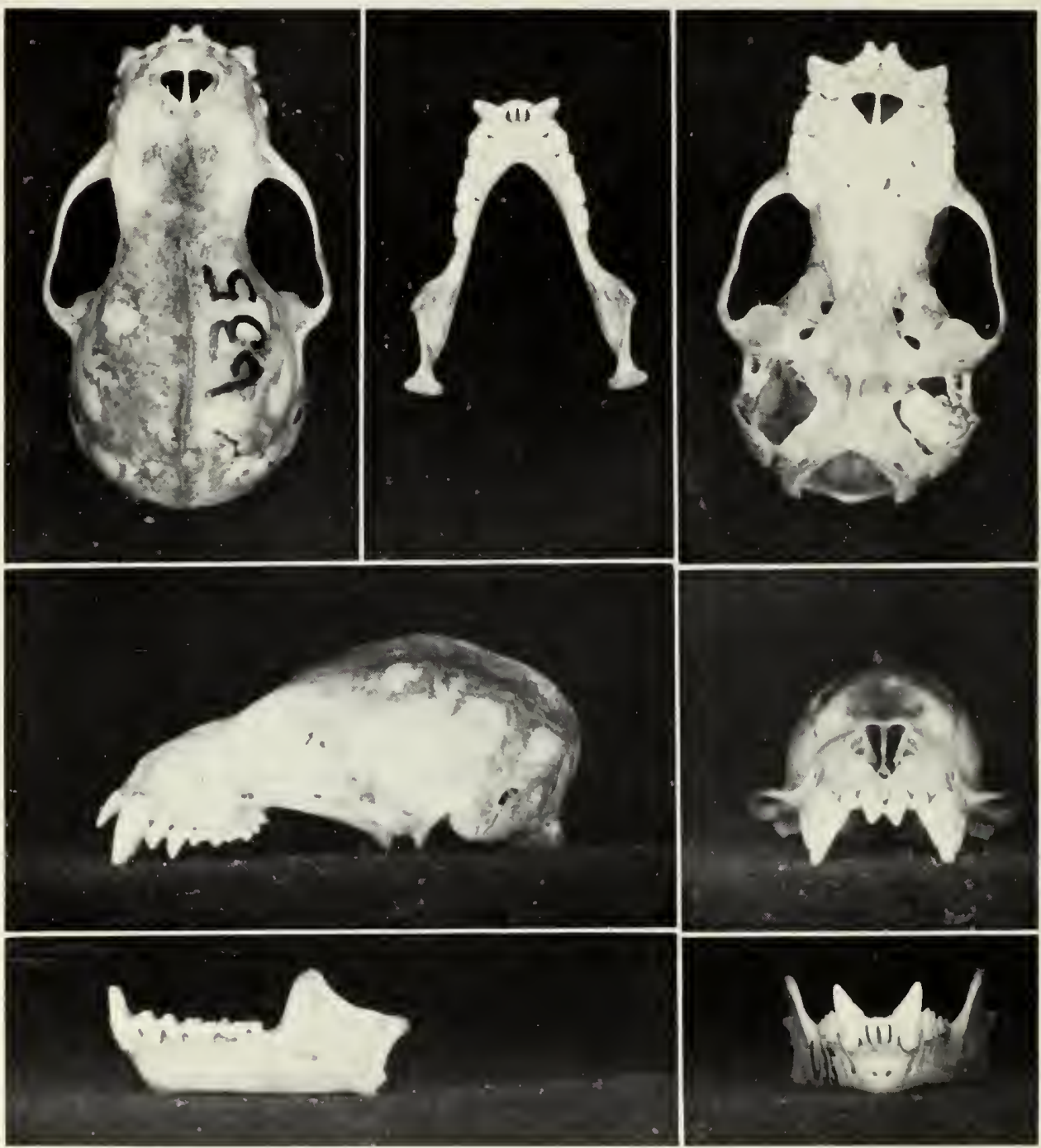

Figure 2

Holotype of Sturnira aratathomasi. $\times 2$. 
were adults, as determined by degree of epiphyseal ossification. Eight of the young adult males (testis of one measured $5 \times 4 \mathrm{~mm}$ ) lacked epaulettes, whereas faint epaulettes were present in one. One adult male lacked epaulettes, four showed faint development (testis of one measured $6 \times 4 \mathrm{~mm}$ ), one moderate development, and 15 prominent development (testis of one measured $8 \times 6$ $\mathrm{mm}$ ). One of 21 females was a young adult which lacked epaulettes. Of the 20 adults, three lacked epaulettes. Two of these females were reproductively inactive, but the third contained a small ( $9 \mathrm{~mm} \mathrm{c}-\mathrm{r}$ length) embryo. Faint epaulettes were seen in three adult females, one with enlarged mammae, and two with embryos 10 and $18 \mathrm{~mm}$ in c-r length. In the 14 adults with well-developed, prominent epaulettes, two had enlarged mammae and 12 contained embryos (two with $13 \mathrm{~mm}$ c-r length embryos and 10 with $20-25 \mathrm{~mm}$ c-r length embryos).

Acknowledgments-We would like to express
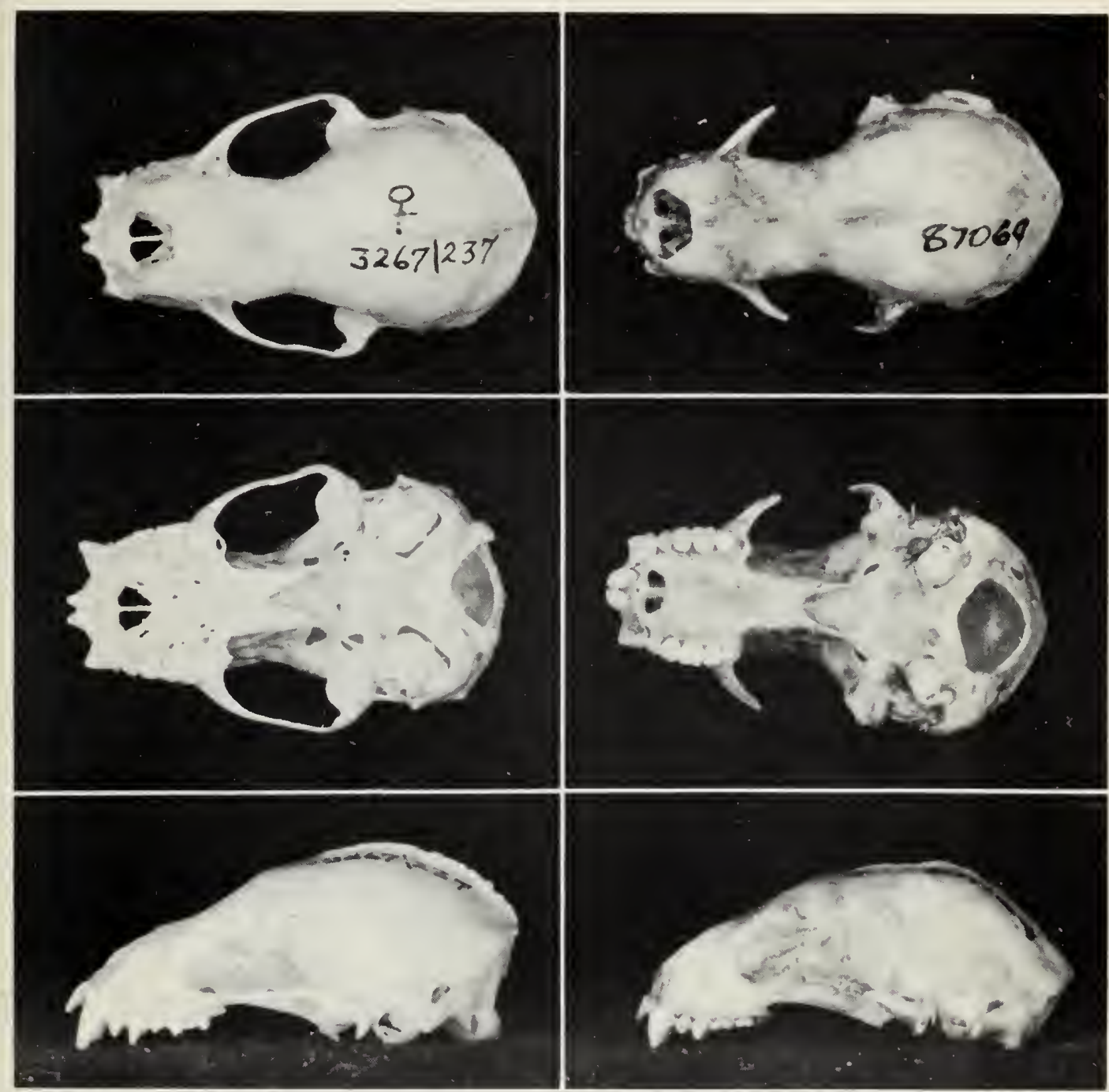

Figure 3

Paratype of S. aratathomasi, ROM No. 46349 \%, from Ecuador, left, compared with paratype of $S$. magna, FMNH No. 87060 \&, right. $\times 2$. 
our gratitude to the following: Dr. Andrew A. Arata and Mr. Maurice Thomas for permission to use the specimen collected by them as the holotype and for other co-operation extended by them; Dr. Xavier Misonne for the opportunity to publish on the material from the collection of Institut Royal des Sciences Naturelles de Belgique and the arrangement permitting an exchange to retain the female paratype in the Royal Ontario Museum; Dr. Joseph C. Moore for the loan of paratypes of $S$. magna from the Field Museum of Natural
History; Mrs. Diana Young and other members of the staff of the Department of Mammalogy, ROM, for their continued co-operation and assistance; and the National Research Council as well as the Canadian National Sportsmen's Show for their financial support of our overall bat research program.

Summary-A new species of Sturnira (Chiroptera, Phyllostomatidae) is described from Colombia and Ecuador and is compared with $S$. magna, the only Sturnira of comparable size.
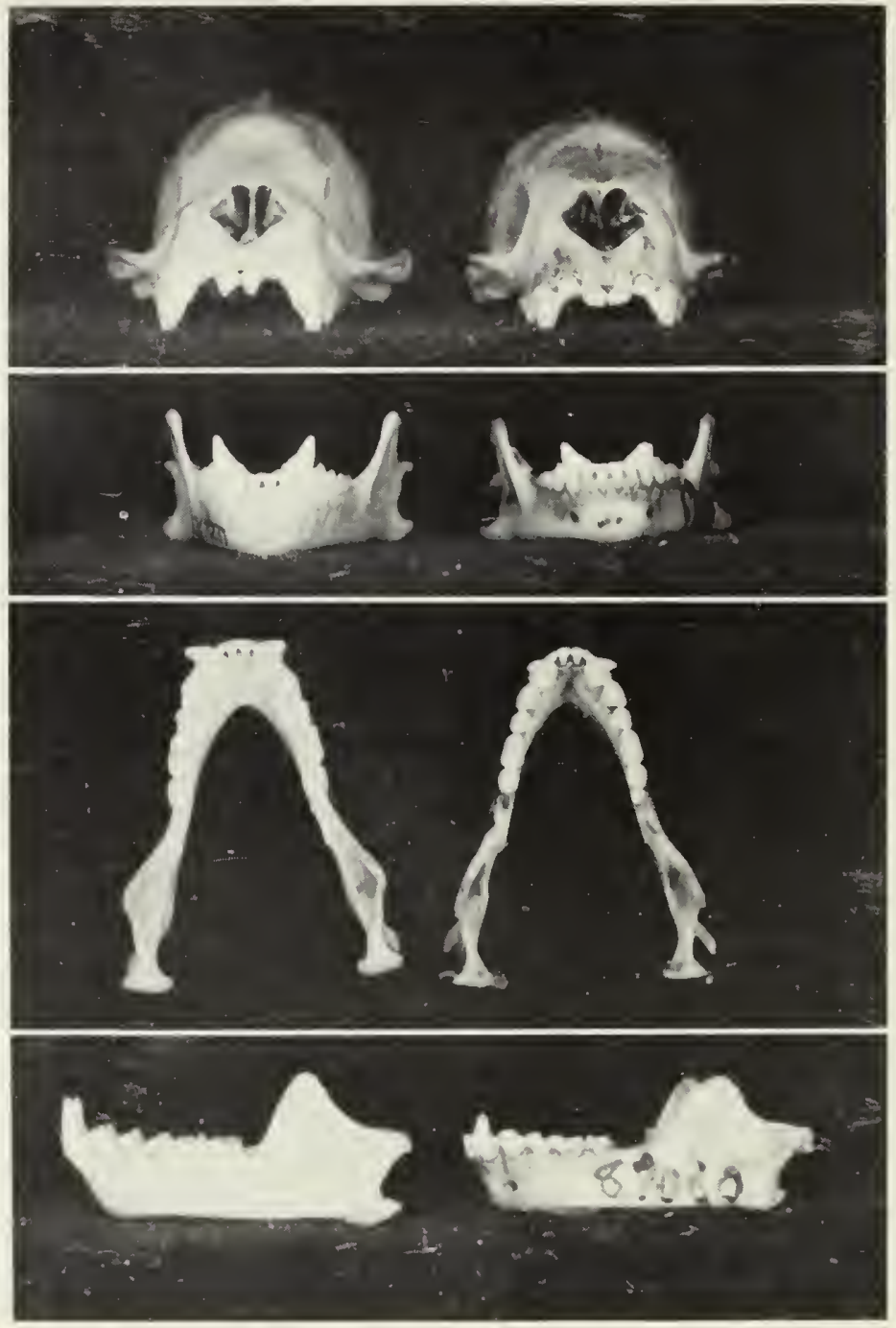

Figure 4

Additional views of ROM No. 46349 , paratype of $S$. aratathomasi (from Ecuador), left, and FMNH No. 87060 \&, paratype of S. magna, right. $\times 2$. 


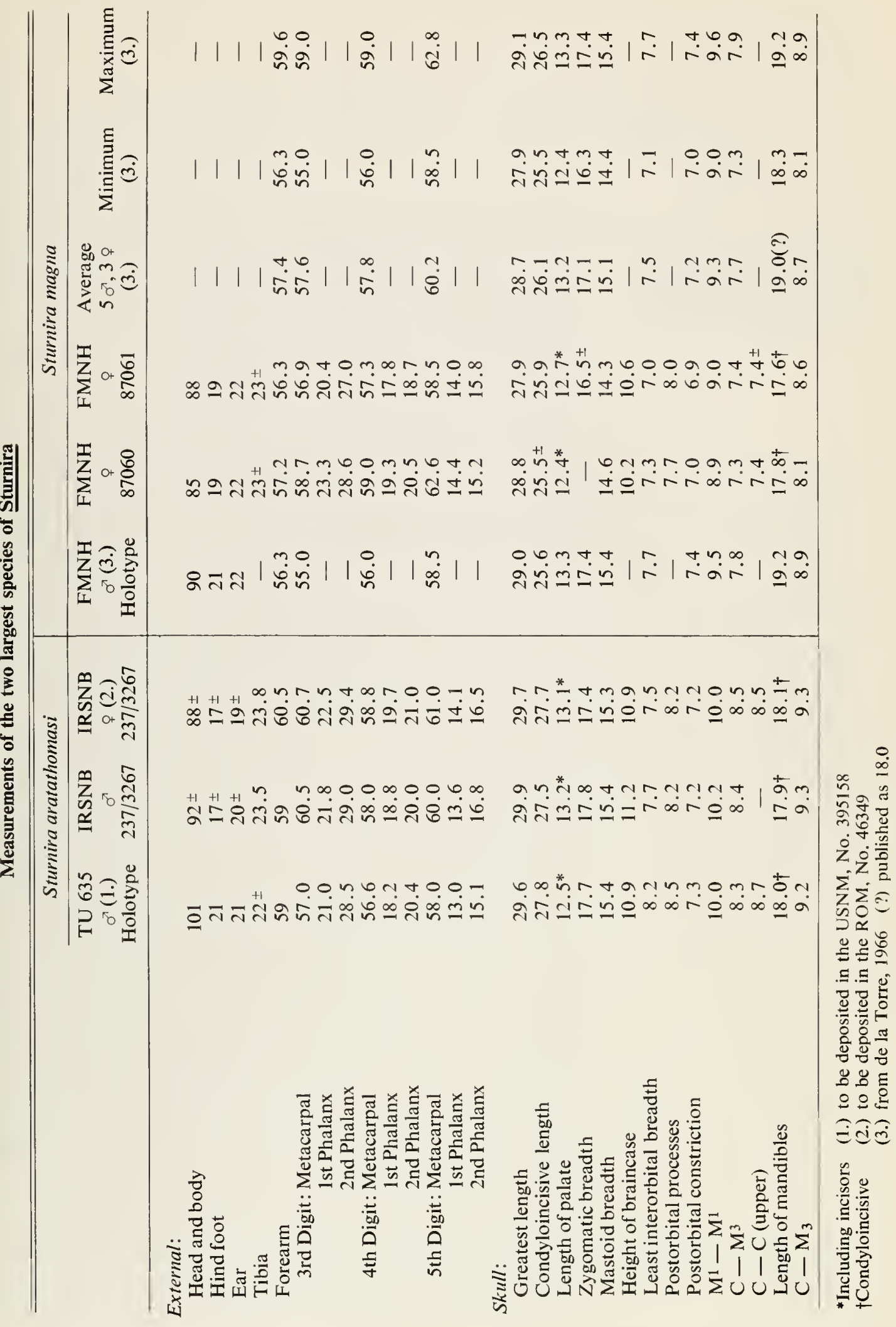




\section{Literature Cited}

de la Torre, Luis

1959 A new species of bat of the genus Sturnira (Phyllostomatidae) from the island of Trinidad, West Indies. Chicago Acad. Sci. Nat. Hist. Misc., No. 166, pp. 1-6

1966 New bats of the genus Sturnira (Phyllostomatidae) from the Amazonian lowlands of Peru and the Windward Islands, West Indies. Proc. Biol. Soc. Wash., Vol. 79, pp. $267-272$

Ridgway, Robert

1912 Color standards and color nomenclature. Washington, D.C., iv., 44 pp., pls. 1-53. 



List Rist

GOYAL ON GIO MARGEIST 

